\title{
Synthesis, Characterization and Saponification of Poly (AN)-Starch Composites and Properties of their Hydrogels
}

\author{
A. Hashem, M.A. Afifi, E.A. El-Alfy and A. Hebeish \\ National Research Centre, Dokki, Cairo, Egypt
}

\begin{abstract}
Hydrogels based on saponified products of poly (acrylonitrile, AN)-starch composites were prepared, characterized and their water abosrbency properties examined. The term composite refered to the resultant products of polymerizatin of AN with starch in presence of ceric ammonium nitrate (CAN) as initiator, that is the composite consists of poly(AN)-starch graft copolymer, homopoly(AN), oxidized starch and unreacted starch. Thus AN monomer was polymerized with gelatinized starch using the ceric ion method. Gelatinization of starch prior to polymerization was affected by heating certain weight of starch in certain volume of distilled water at different temperrature $\left(65,75\right.$ and $\left.85^{\circ} \mathrm{C}\right)$. Polymerization was carried out under a variety of coditions. Saponification of poly (AN)-starch composites was performed in sodium hydroxide to yield the hydrogels. The water absorbency properties of these hydrogels were found to rely on variables affecting the magnitudes of both polymerization and saponification. Among these variables mention was made of the starch/liquor ratio, cocentration of ceric ammonium nitrate (CAN), monomer/starch molar ratio, duration of grafting and gelatinization temperature as well as saponification time. Hydrogels display their maximum water absorbency when granular starch was firstly gelatinized at $85^{\circ} \mathrm{C}$ for $30 \mathrm{~min}$ and secondly subjected to polymerization with AN using AN/starch molar ratio of 4.8 and CAN concentration of $10 \mathrm{mmol} / \mathrm{L}$ liquor ratio of 12.5 and thirdly sample of the so obtained poly (AN)-starch composite was saponified in sodium hydroxide $(0.7 \mathrm{~N})$ at $95^{\circ} \mathrm{C}$ for $180 \mathrm{~min}$. The saponified product was then precipitated in excess methanol, dried and finally converted into powder. The product (hydrogel) in the powder form exhibited maximum water absorbency of $920 \mathrm{~g}$ water per gram hydrogel and $38 \mathrm{~mL}$ synthetic urine per gram hydrogel.
\end{abstract}

Key words: Saponificaiton, Poly (AN)-starch Composites, Hydrogels, Water Absorbancy

\section{INTRODUCTION}

Hydrogels are three- dimensional hydrophilic polymer network capable of imbibing large amounts of water. For this reason they have been used widely in the field of biomedicine and pharmacy such as soft contact lences, wound dressing, superabsorbents and drug delivery system [1-5]. They have also been used in agriculture as soil protection as gel slurry to the root zone of the plants before transplanting, prevents root from drying, reduces wilting and transplant shock and improves plant survival [6, 7]. Although hydrogels based synthetic polymers such as polyacrylamide, polyacrylic acid, poly vinyl alcohol (PVA), poly vinyl pyrrolidone and polyethylene oxide have been extensively studied yet their properties need to be improved further for special applications $[8,9]$. On the other hand, hydrogels of natural polymers, especially polysaccharides, have recently found widespread applications because of their unique advantages. Polysaccharides are, in general, non-toxic, biocompatible, biodegradable and abundant [10, 11]. The hydrogels based on saponified starch graft copolymer are widely used in consumer products such as adult incontinence pads, diapers and sanitary products [12].

Among root starches those posses inherent high water swelling capacity, potato starch shows a very rapid and exceptionally high swelling at relatively low temperature. Potato starch has been preferably used in the preparation of hydrogels. On the other hand, the cereal starch such as maize starch has comparatively low swelling power and hence there is a need to improve their swelling power by chemical modification, particularly through the grafting with hydrophilic monomers.

The present study was undertaken with a view to enhance the water absorption capacity of maize starch by subjecting the latter to the following consequence of treatments 1) gelatinization of starch at different temperature, 2) polymerization of $\mathrm{AN}$ with gelatinized starch using ceric ammonium nitrate (CAN ) as initiator , 3) saponification of poly(AN)-starch composites under the influence of sodium hydroxide and 4) precipitation of the saponified starch composite and its drying and grinding to give ultimately the hydrogel in powder form. Also studied was the dependence of the water absorbancy of the hydrogel on temperature of 
gelatinization and on factors affecting polymerization of AN with gelatinized starch, namely liquor ratio, CAN concentration, AN/starch molar ratio and temperature and duration of polymerization as well as on the saponification time.

\section{MATERIALS AND METHODS}

Materials: Starch: maize starch was kindly supplied by the Egyptian Starch and Glucose Manufacturing Company, Cairo, Egypt.

Monomer: Acrylonitrile (AN) was supplied by B.D.H. as reagent grade. It was used without further purification.

Initiator: Ceric ammonium nitrate (CAN) was also supplied by B.D.H. as reagent grade.

Other Reagents: All other reagents used were of reagent grade chemicals and used without farther purification.

Graft Copolymerization: Poly (AN)-starch composite was prepared according to a reported method [13] as follows:

Dried starch (5 g) in a known volume of distilled water was gelatinized by heating at different temperature $(65$, 75 and $85^{\circ} \mathrm{C}$ ) for $30 \mathrm{~min}$ in a $100 \mathrm{~mL}$ Erlenmeyer flask in thermostatic water-bath. Then, the so obtained gelatinized starch was cooled to $30-33^{\circ} \mathrm{C}$ and variable quantities of $\mathrm{AN}$ were added to obtain different molar ratios of $\mathrm{AN} / \mathrm{starch}$. The freshly prepared solutions of $\mathrm{CAN}$ in $3 \mathrm{~mL}$ of $1 \mathrm{~N} \mathrm{HNO}_{3}$ were added for attaining different concentrations of $\mathrm{Ce}$ (IV) ions. The polymerization reaction was allowed to proceed at $30-33^{\circ} \mathrm{C}$ for the desired reaction time under stirring. The whole volume of the resulting mixture was divided into two portions. One portion was reserved for saponification as described below to obtain the hydrogel and the other portion was precipitated with $200 \mathrm{~mL}$ of $95 \%$ ethanol. The precipitate was separated by filtration and dried in an electric oven at $60^{\circ} \mathrm{C}$ for $3 \mathrm{~h}$. The percentage of homopolymer and the graft $\%$ were calculated after characterization of the final sample by the following procedures:

\section{Characterization of Poly (AN)-starch Graft Copolymer}

Extraction of Homopolymer: Certain amount of the final polymerization products (composite), $1 \mathrm{~g}$ was added to $100 \mathrm{~mL}$ of $\mathrm{N}, \mathrm{N}^{-}$dimethyl formamide (DMF) in a glass stoppered Erlenmeyer flask at room temperature while stirring on magnetic stirrer for $30 \mathrm{~h}$. After each $5 \mathrm{hrs}$ the sample was centrifuged at $4000 \mathrm{rpm}$ for $10 \mathrm{~min}$. The clear solution containing the homopolymer was decanted. After completion of time (no precipitate with new DMF addition), the sample was washed with ethanol and dried at $60^{\circ} \mathrm{C}$. The graft yield was calculated from the nitrogen content of the sample after extraction of homopolymer as follows [14].

$$
\text { Graft Yield } \%=\frac{\text { Wt. of grafted poly }(\mathrm{AN})(\mathrm{g}) \times 100}{\text { Wt. of starch }(\mathrm{g})}
$$

Graft Yield $\%=\frac{\text { N\% X 53/14 X 100 }}{100-(\mathrm{N} \% \text { X 53/14) }}$

Where, 53 is the molecular wt. of $\mathrm{AN}$ and 14 is the atomic wt. of $\mathrm{N}$

$$
\text { Graft Yield } \%=\frac{\mathrm{N} \% \times 3.79 \times 100}{100-(\mathrm{N} \% \times 3.79)}
$$

Alkaline Saponification: A suspension of $1.0 \mathrm{~g}$ of poly (AN)-starch composite in $9 \mathrm{~mL} 0.7 \mathrm{~N} \mathrm{NaOH}$ was introduced in a weighing bottle and mixed well. The bottle (loosely stopered to permit escape of ammonia) was then placed in an electric oven at $95^{\circ} \mathrm{C}$ for desired time to complete the saponification (the colour is changed from deep red to light yellow). The mixture was dispersed in $200 \mathrm{~mL}$ methanol using electric blender for $5 \mathrm{~min}$ and then poured into an excess of ethanol. The precipitate was washed with slightly acidified ethanol (ethanol with few drops of acetic acid) until $\mathrm{pH} 8$, then filtered and dried at $60^{\circ} \mathrm{C}$ for $3 \mathrm{~h}$.

Absorbency or Swelling Measurement: Absorbency of superabsorbent polymers are measured by the free swelling method and expressed as a water retention value (WRV) calculated in grams of water per grams of dry polymer. Thus, an accurately weighed quantity of the hydrogel under investigation $(0.1 \mathrm{~g}$ ) was immersed in $100 \mathrm{~mL}$ of distilled water at room temperature for 30 min and allowed to stand to full hydration of the hydrogel was achieved. The swollen hydrogel was then separated from unabsorbed water by screening through a tared 100 to 150 mesh sieve. The hydrogel was allowed to drain on the sieve for $10 \mathrm{~min}$ and the sieve was then weighed to determine the weight of water which caused swelling of the hydrogel. Water absorbency or swelling characteristic was calculated as $\mathrm{g} / \mathrm{g}$ using the following equation:

Water retention value $(\mathrm{g} / \mathrm{g})=\mathrm{W}_{2}-\mathrm{W}_{1}$

$$
\mathrm{W}_{1}
$$

Where, $\mathrm{W}_{2}$ and $\mathrm{W}_{1}$ are the weights of water swollen hydrogel and dry absorbent in grams, respectively. A similar absorbency test was run in synthetic urine [0.64 
$\mathrm{g} \mathrm{CaCl}_{2}, 1.14 \mathrm{MgSO}_{4} .7 \mathrm{H}_{2} \mathrm{O}, 8.2 \mathrm{~g} \mathrm{NaCl}, 20 \mathrm{~g}$ urea and $1000 \mathrm{~g}$ distilled water].

\section{RESULTS AND DISCUSSION}

Previous reports [13, 15] have dealt with grafting of acrylonitrile to granular starch and, to some extent, heat-pretreated starch using the $\mathrm{Ce}^{+4}$ initiation system. Saponification of poly (AN)-starch graft copolymer gave superabsorbent material. The gelatinization of starch prior to grafting increases the water absorption capacity.

In the current study when maize starch was subjected to heat treatment to give gelatinized starch and the latter was polymerized with AN followed by Saponification of the resultant polymerization products, several reaction take place. Among these are the reactions suggested by equations 1-6.

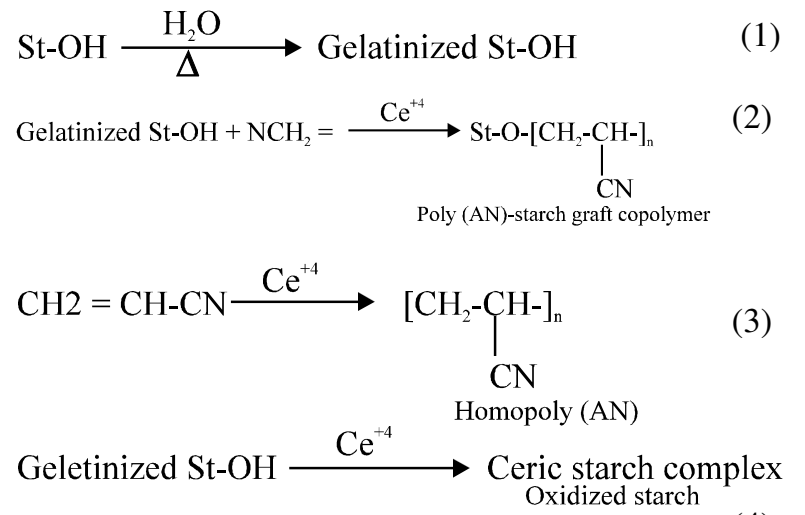

St-O- $\left[\mathrm{CH}_{2}-\left.\right|_{\mathrm{CN}} ^{\mathrm{CH}-}\right]_{\mathrm{n}} \stackrel{\mathrm{NaOH}}{\longrightarrow} \mathrm{St-O}-\left[\mathrm{CH}_{2}-\mathrm{CH}-\right]_{\mathrm{x}}\left(-\mathrm{CH}_{2}-\mathrm{CH}-\right)_{\mathrm{y}}$

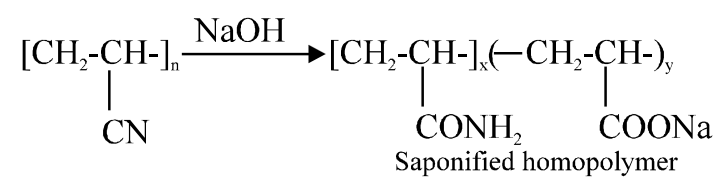

Where, $\mathrm{n}=\mathrm{x}+\mathrm{y}$

The composite is represented by the reaction products of equations 1-4 whereas the hydrogel is represented by equations 5 and 6 .

The above reaction scheme indicates that grafting is associated with the homopolymer formation and starch oxidation. It also indicates that saponification converts the same grafted poly (AN) chain and homopoly (AN) chain with cyano group ( $-\mathrm{C}=\mathrm{N}$ ) as the main group to both amide $\left(-\mathrm{CONH}_{2}\right)$ and carboxylate (-COONa) groups. At any event, however, the magnitudes of starch reactions would be anticipated to depend upon the treatment conditions used to achieve gelatinized starch, poly (AN)-composite and hydrogel. Factors controlling the magnitude of each treatment would also posses their impact on water absorbency properties of the hydrogel. All these, indeed, are clarified by the studies given below.

Liquor Ratio: Table 1 shows the effect of liquor ratio on the graft yield obtained from grafted samples and nitrogen percentages of composite and graft copolymer. The graft yield\% decreases significantly by increasing liquor ratio from 7.5 to 15 (Table 1). The situation is more aggravated by using higher liquor ratios. The decreasing in the graft yield\% by increasing the liquor ratio was attributed to two main reasons. The first reason, higher liquor ratio is associated with higher dilution that is the concentration of reactants in the grafting medium becomes lower. The second reason is consequence of the first where dilution decreases the probability of the molecular collision of reactants leading to the decrease in the grafting.

A close examination of the $\mathrm{N} \%$ of both composite and graft copolymer (Table 1) reveals that the values of $\mathrm{N} \%$ of the graft copolymer are marginally lower than those of the composite (due to homopolymer in composite) up to a liquor ratio of 15. Much significant lower values are observed when polymerization was performed using higher liquor ratio i.e. 17.5 or 20.0, which follows the same explanation as above.

Polymerization Condition: AN/starch molar ratio, 3.2; CAN $10 \mathrm{mmol} / \mathrm{L}$; temp., $30-33^{\circ} \mathrm{C}$ for $1 \mathrm{~h}$. Table 2 shows the effect of saponification process of composite on the liquor ratio and water retention value. It is clear from Table 2 that the nitrogen percent of composite is much higher than nitrogen\% of the hydrogel, (after saponification), for all samples under investigation. The decreasing in nitrogen\% of hydrogel, could be attributed to: 1) the conversion of the cyano groups in some of the grafted poly (AN) and homopoly (AN) chains into amide $\left(-\mathrm{CONH}_{2}\right)$ and carboxylate ($\mathrm{COONa}$ groups. This was also explained from the values of carboxyl content of the saponified composite (Table 2) and from equation 5, 6 and 2) during the saponification and precipitation, the hydrogel losses low molecular weight fractions which are rich with carboxylate groups, highly soluble and can not be precipitated under condition used. It is under standable that the carboxylate groups are formed on the expense of $-\mathrm{C}=\mathrm{N}$ and $-\mathrm{CONH}_{2}$ groups. Removal of the said low molecular weight products during saponification and precipitation as we as the values of carboxyl content obtained from saponification would counterbalance the loss in N\% after saponification.

The increase in $\mathrm{N} \%$ of hydrogel by increasing the liquor ratio, explain that, there is an optimal ratio necessary to form the hydrogel. 
Table 1: Effect of Liquor Ratio on the Graft Yield\% and Nitrogen Percentages of Composite and Graft Copolymer

\begin{tabular}{lccc}
\hline Liquor ratio & N\% in composite & N\% in graft copolymer & Graft yield\% \\
\hline 7.5 & 10.92 & 10.37 & 64.75 \\
10.0 & 10.70 & 10.26 & 63.63 \\
12.5 & 10.64 & 10.14 & 62.42 \\
15.0 & 10.43 & 9.28 & 54.25 \\
17.5 & 9.35 & 6.07 & 29.88 \\
20.0 & 9.25 & 5.92 & 28.93 \\
\hline
\end{tabular}

Table 2: Effect of Liquor Ratio on Saponification Process of Composite and Water Retention Values

\begin{tabular}{lcccc}
\hline Liquor ratio & $\begin{array}{l}\text { N\% in } \\
\text { composite }\end{array}$ & $\begin{array}{l}\text { N\% in } \\
\text { hydrogel }\end{array}$ & $\begin{array}{l}\text { Carboxyl content } \\
\text { m.eq./100 g sample }\end{array}$ & WRV \\
\hline 7.5 & 10.92 & 2.896 & 386.45 & 404 \\
10.0 & 10.70 & 2.968 & 391.11 & 551 \\
12.5 & 10.64 & 3.11 & 397.0 & 617 \\
15.0 & 10.43 & 2.818 & 382.33 & 612 \\
17.5 & 9.35 & 2.676 & 375.3 & 487 \\
20.0 & 9.25 & 2.640 & 367.6 & 480 \\
\hline
\end{tabular}

Saponification Condition: One gram of poly (AN)-starch composite, 9mL of $0.7 \mathrm{~N} \mathrm{NaOH}$; saponification temp., $95^{\circ} \mathrm{C}$; saponification time, $2 \mathrm{~h}$.

Table 3: Effect of CAN Concentration on the Graft Yield\%, Nitrogen Percentages of Composite and Graft Copolymer and Water Retention Values

\begin{tabular}{llccr}
\hline $\begin{array}{l}\text { CAN conc. } \\
(\mathrm{mmol} / \mathrm{L})\end{array}$ & $\begin{array}{l}\text { N\% in } \\
\text { composite }\end{array}$ & $\begin{array}{l}\mathrm{N} \% \text { in } \\
\text { hydrogel }\end{array}$ & $\begin{array}{l}\text { Graft } \\
\text { yield } \%\end{array}$ & WRV \\
\hline 1.0 & 022.0 & 0.20 & 0.57 & Zero \\
2.0 & 6.04 & 1.741 & 15.0 & 185 \\
2.5 & 9.48 & 2.68 & 39.7 & 296 \\
5.0 & 10.30 & 2.901 & 61.1 & 526 \\
10.0 & 10.64 & 2.97 & 62.4 & 617 \\
20.0 & 11.59 & 3.11 & 70.28 & 451 \\
40.0 & 12.2 & 3.35 & 51.8 & 400 \\
\hline
\end{tabular}

Polymerization Condition: L.R., 12.5, AN/Starch molar ratio, 3.2; temp., $30-33^{\circ} \mathrm{C}$ for $1 \mathrm{~h}$.

Saponification Condition: One gram of poly (AN)-starch composite, $9 \mathrm{~mL}$ of $0.7 \mathrm{~N} \mathrm{NaOH}$; saponification temperature, $95^{\circ} \mathrm{C}$; saponification time, $2 \mathrm{~h}$.

The maximum water retention value (Table 2) was obtained at liquor ratio of 12.5 . Table 2 shows that the water retention values increasing up to a maximum value of $617 \mathrm{~g}$ water/g hydrogel at a liquor ratio of 12.5 . A decrease in the water retention value has been seen upon further increase in the liquor ratios from 617 to $480 \mathrm{~g} \mathrm{H}_{2} \mathrm{O} / \mathrm{g}$ hydrogel at liquor ratio of 12.5 and 20 , respectively. This suggests a liquor ratio of 12.5 constitutes the optimal ratio for the hydrogel formation to assume maximum water absorbency. The increase in the water absorbency is not only due to graft formation but also due to the gelatinization effect on the starch backbone which undergoes physical changes. The main physical changes may occur in starch structure is an increase in the disruption of starch molecules i.e. an increase in the disorder regions in starch structure on the expense of the order regions. Therefore, the gelatinization effect is mainly due to the increase in the free volume of starch chains which in combination with its hydrophilicity, makes it capable to absorb a large volume of water.

Initiator Concentration: Table 3 shows the effect of CAN concentration on the graft yield\%, $\mathrm{N} \%$ of both composite and graft copolymer and, the impact of this on the water retention value of the hydrogel. The results signify that increasing the CAN concentration up to 20 m.mole/l is accompanied by enhancement in the graft yield\%, N\% of composite and $\mathrm{N} \%$ of graft copolymer. It should be noted however, that the magnitude of this enhancement is striking up to 5 mmole/L CAN and not so at higher CAN concentrations i.e., 10 and $20 \mathrm{mmole} / \mathrm{L}$. Further increase in CAN concentration up to $40 \mathrm{~m} . \mathrm{mole} / \mathrm{L}$ CAN causes a decrease in both graft yield $\%$ and $\mathrm{N} \%$ of the copolymer while increasing the $\mathrm{N} \%$ of the composite. Increment of graft yield\% and 
$\mathrm{N} \%$ of the copolymer by increasing CAN concentration up to $20 \mathrm{mmol} / \mathrm{L}$ could be interpreted in terms of increased creation of free radical on starch backbone to which AN molecule is addad thereby initiating grafting. Subsequent addition of AN molecules to the initiated grafted chain causes propagation of the graft. Beside initiation the $\mathrm{Ce}^{+4}$ participate in termination of the graft. It is logical that abundance of free radicals speed up the rate of termination and this indeed explain the decrease in graft yield\% and N\% of the copolymer when concentration of CAN as high as $40 \mathrm{mmole} / \mathrm{L}$ was used . In combination with faster termination is the increased homopolymer formation at higher concentration of CAN (i.e., $40 \mathrm{mmole} / \mathrm{L}$ ); homopolymerization and grafting are two competitive reactions. The increase in the N\% of composite by increasing CAN could be attributed to the favourable effect of CAN on homopolymer formation.

It is clear from Table 3 that the water retention values increase from zero to $617 \mathrm{~g} \mathrm{H}_{2} \mathrm{O} / 1 \mathrm{~g}$ hydrogel by increasing the concentration of CAN from 1 to $10 \mathrm{mmol} / \mathrm{L}$, respectively. A further increase in the CAN concentration above $10 \mathrm{mmol} / \mathrm{L}$ was accompanied by decrease in water retention vale. The enhancement in water retention value by increasing CAN concentration to a maximum limit explain the role of specific amount of CAN to create the free volume which capable to absorb maximum amount of water.

Monomer/Starch Molar Ratio: Table 4 shows the effect of AN/starch molar ratio, graft yield\%, $\mathrm{N} \%$ of composite and hydrogel on water retention value. It clear that increasing the $\mathrm{AN} / \mathrm{starch}$ molar ratio from 0.8 to 6.4 brings about enhancement in the graft yield from 9.4 to $87.33 \%$. Saponification of poly(AN)-starch composite prepared using AN/starch molar ratios ranging from 0.8 to 6.4 gave hydrogels with values ranging from 1.22 to $4.066 \% \mathrm{~N}$. Obviously then the poly(AN)-starch composite synthesized at different AN/starch molar ratio followed by saponification produces hydrogels which are characterized by lower values of $\mathrm{N} \%$ as compared with the $\mathrm{N} \%$ of composite due to conversion of some cyano groups in graft and homopolymer (in composite) into amide and carboxylate groups during saponification. The hydrogels obtained have excellent water absorbency properties as evidenced by the results of water retention values (Table 4). Water retention value increases by increasing the AN/starch molar ratio to 4.8 where the water retention value reach to $796 \mathrm{~g}$ water/1 $\mathrm{g}$ hydrogel. At AN/starch molar ratio of 6.4 , the water retention value is equal $430 \mathrm{~g}$ water per $1 \mathrm{~g}$ hydrogel. The fall in water retention value at higher $\mathrm{AN} / \mathrm{starch}$ molar ratio could be ascribed to crosslinking reaction occurring between poly (AN) chains during saponification of composite which contain higher amount of both copolymer and homopolymer as well be illustrated later, in accordance with previous studies dealing with saponification of starch grafted with poly(AN) [16].

It is understandable that the increase in the graft yield\% and $\mathrm{N} \%$ of composite by increasing AN/starch molar ratio is a manifestation of greater availability of AN molecules in the vicinity of the gelatinized starch macroradicals. By virtue of their immobility, reaction of starch macroradical would rely on availability of AN molecules in the proximity, a situation which is justified at higher AN/starch molar ratios. Similarly, high concentration of AN molecules in the polymerization medium help establish better probability for molecular collision thereby leading to increased homopolymerization .

Based on the above results it may be concluded that the water absorption capacity of hydrogels derived from poly(AN)-starch composites via alkaline saponfication is determined by the amounts of both graft and homopolymer in the composite as will as physical changes in the molecular structure of the starch composite as a whole. Current results suggest that these physical changes which accompany the chemical changes during grafting, homopolymerization and saponification come to play a role in determing the capacity of the hydrogel to absorb water.

Table 4: Effect of Monomer/Starch Molar Ratio on the Graft Yield\% of Poly (AN)-Starch Graft Copolymer, the N\% of Composite and N\% of Hydrogels Derived From Poly (AN)-Starch Composite Along With the Onset of this on Water Retention Value

\begin{tabular}{llccc}
\hline $\begin{array}{l}\text { AN/Starch } \\
\text { molar ratio }\end{array}$ & $\begin{array}{l}\text { N\% } \\
\text { in composite }\end{array}$ & $\begin{array}{l}\text { N\% } \\
\text { in hydrogel }\end{array}$ & $\begin{array}{l}\text { Graft } \\
\text { Yield }(\%)\end{array}$ & $\begin{array}{l}\text { WRV } \\
(\mathrm{g} / \mathrm{g})\end{array}$ \\
\hline 0.8 & 2.65 & 1.22 & 9.4 & 132 \\
1.6 & 6.49 & 2.04 & 28.4 & 302 \\
2.4 & 9.21 & 2.39 & 45.9 & 435 \\
3.2 & 10.64 & 2.82 & 62.42 & 617 \\
4.0 & 12.95 & 3.76 & 77.3 & 650 \\
4.8 & 13.23 & 3.83 & 84.06 & 796 \\
6.4 & 13.80 & 4.07 & 87.33 & 430 \\
\hline
\end{tabular}

Polymerization Condition: L.R., 1: 12.5; [CAN] 10 m.mole/L; temp., 30-33 for 1h.

Saponification Condition: Grafted starch, $1 \mathrm{~g} ; 9 \mathrm{~mL}$ of $0.7 \mathrm{~N} \mathrm{NaOH}$; saponification temp., $95^{\circ} \mathrm{C}$; saponification time, $2 \mathrm{~h}$. 


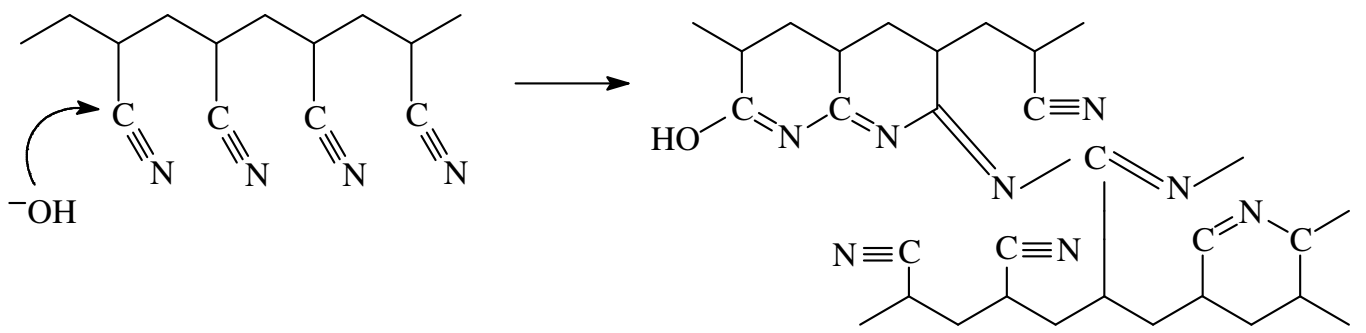

Table 5: Effect of Saponification Time on the Water Retention Value of Hydrogel Prepared From Poly (AN)-Starch Composite

\begin{tabular}{lrrrrrrr}
\hline Time (min) & 30 & 60 & 90 & 120 & 150 & 180 & 240 \\
WRV $(\mathrm{g} / \mathrm{g})$ & 142 & 267 & 495 & 751 & 780 & 805 & 678 \\
\hline
\end{tabular}

Saponification Condition: Grafted starch (G. Y.\% = 83.4\%), $1 \mathrm{~g} ; 9 \mathrm{~mL}$ of $0.7 \mathrm{~N} \mathrm{NaOH}$; saponification temp., $95^{\circ} \mathrm{C}$.

Table6: Effect of Gelatinization Temperature Prior to Polymerization on Water Retention Value of Poly(AN)-Starch Composite, Graft Yield\%, N\% of Composite and N\% of the Hydrogel Derived From Poly(AN)-Starch Composite

\begin{tabular}{llcll}
\hline $\begin{array}{l}\text { Gelatinization } \\
\text { Temp. }\left({ }^{\circ} \mathrm{C}\right)\end{array}$ & $\begin{array}{l}\text { N\% } \\
\text { in Composite }\end{array}$ & $\begin{array}{l}\text { N\% } \\
\text { in Graft }\end{array}$ & $\begin{array}{l}\text { Graft Yield } \\
(\%)\end{array}$ & WRV $(\mathrm{g} / \mathrm{g})$ \\
\hline 65 & 14.97 & 1.45 & 110.7 & 361 \\
75 & 13.73 & 4.1 & 86.6 & 857 \\
85 & 12.82 & 3.9 & 86.0 & 866 \\
\hline
\end{tabular}

Polymerization Condition: L.R., 12.5; [CAN], 10 m.mole/L; AN/starch molar ratio, 4.8; reaction temp., 30-33 for $1 \mathrm{~h}$.

Saponification Condition: Saponification temp., $95^{\circ} \mathrm{C}$; saponification time, $3 \mathrm{~h}$.

Table 7: Effect of Duration of Polymerization on the Graft Yield\% of Poly(AN)-Starch Graft Copolymers, the N\% of Composite and the N\% of Hydrogels Derived From Poly(AN)-Starch Composite Along With the Onset of this on Water Retention Value

\begin{tabular}{lllcc}
\hline $\begin{array}{l}\text { Duration } \\
\text { Time }(\mathrm{min})\end{array}$ & $\begin{array}{l}\text { N\% } \\
\text { in composite }\end{array}$ & $\begin{array}{l}\text { N\% } \\
\text { in hydrogel }\end{array}$ & $\begin{array}{l}\text { Graft } \\
\text { Yield }(\%)\end{array}$ & $\begin{array}{c}\text { WRV } \\
(\mathrm{g} / \mathrm{g})\end{array}$ \\
\hline 15 & 12.3 & 3.8 & 82.03 & 690 \\
30 & 12.5 & 3.9 & 84.19 & 700 \\
60 & 12.82 & 4.23 & 87.33 & 866 \\
90 & 13.20 & 4.4 & 88.40 & 896 \\
120 & 13.50 & 4.5 & 88.94 & 913 \\
150 & 13.75 & 4.6 & 99.36 & 920 \\
180 & 14.0 & 4.3 & 87.73 & 920 \\
\hline
\end{tabular}

Polymerization Condition: L.R.; 12.5; [CAN], 10 m.mole/L ; AN/starch molar ratio, 4.8; reaction temp., 30-33 ${ }^{\circ} \mathrm{C}$

Saponification Condition: $1 \mathrm{~g}$ grafted starch; $9 \mathrm{~mL}$ of $0.7 \mathrm{~N} \mathrm{NaOH}$; saponification temp., $95^{\circ} \mathrm{C}$; saponification time, $3 \mathrm{~h}$.

Saponification Time: As already stated during the alkaline saponification of poly(AN)-starch composites at $95^{\circ} \mathrm{C}$, the nitrile groups are converted into a mixture of amide and carboxylate groups and intermediate coloured products are formed [15]. The colouration was attributed to the formation of a partly hydrogenated naphthiridine type structure which is initiated by the necleophilic attack of $\mathrm{OH}^{-}$on the carbon atom of the nitrile group. Insolubility of the polymer is known to occur during this step and is explained by "propagation crosslinks" between interchain neighboring nitrile groups as suggested by equation 7 .
Amide/carboxylate ratios during saponification will vary depending on saponification conditions but are typically on the order of $1 / 2$. Complete saponification to give poly (sodium acrylate) grafts does not occur [15].

Table 5 shows the effect of saponification time on the water retention value of hydrogels derived from poly (AN)-starch composite.

It is clear (Table 5) that the water retention value increases by increasing the time of saponification within the range 30-180 min to reach a maximum of $805 \mathrm{~g}$ water per $1 \mathrm{~g}$ hydrogel. Further increase in the saponification time leads to a decrease in water 
Table 8: Ability of Hydrogels Having Different N\% Prepared From Poly (AN)-Starch Graft Copolymers With Various Graft Yield Via Alkaline Saponification to Absorb Synthetic Urine and Distilled Water

\begin{tabular}{llllc}
\hline $\begin{array}{l}\text { N\% } \\
\text { in composite }\end{array}$ & $\begin{array}{l}\text { N\% } \\
\text { in hydrogel }\end{array}$ & $\begin{array}{l}\text { Graft } \\
\text { Yield }(\%)\end{array}$ & $\begin{array}{l}\text { WRV } \\
(\mathrm{g} / \mathrm{g})\end{array}$ & $\begin{array}{l}\text { Urine Retention } \\
\text { Value }\end{array}$ \\
\hline 2.65 & 1.22 & 9.4 & 132 & 15 \\
6.49 & 2.04 & 28.4 & 302 & 20 \\
9.21 & 2.39 & 45.9 & 435 & 28 \\
10.64 & 2.82 & 62.42 & 617 & 29 \\
12.95 & 3.76 & 77.3 & 650 & 31 \\
13.23 & 3.83 & 84.06 & 796 & 35 \\
13.8 & 4.066 & 87.33 & 430 & 38 \\
\hline
\end{tabular}

retention value. This could be interpreted in terms of greater conversion of the amide groups to carboxylate groups at longer saponification time. That is, the carboxylate groups increases as the time of saponification increases and the water retention values are only due to insoluble graft copolymer. This behavior has been reported for similar experiments with different starches [16].

Gelatinization Temperature: Table 6 shows the effect of gelatinization temperature on the graft yield $\%$ and the N\% of both composite and hydrogel derived from poly (AN)-starch composite. Dependence of water retention value on changes in the values of graft yield $\%$ and $\mathrm{N} \%$ percentages are also shown in the same Table. Gelatinization of maize starch was conducted at different temperature, via, 65,75 and $85^{\circ} \mathrm{C}$. The gelatinized starches so obtained served as the parent substrate for grafting with $\mathrm{AN}$ under the initiation action of CAN. The resultant poly (AN)-starch composites were subjected to saponification with the purpose of synthesizing the hydrogels.

It is seen (Table 6) that gelatinization of starch prior to grafting decreases the susceptibility of starch to grafting, gelatinization temperature $75^{\circ} \mathrm{C}$ and $85^{\circ} \mathrm{C}$ brings about starch candidates with lower susceptibility to grafting than conditions of gelatinization at $65^{\circ} \mathrm{C}$. This is evidenced by the results of graft yield $\%$ and N\% of composite. At 75 and $85^{\circ} \mathrm{C}$, it is likely that gelatinization converts starch to highly swollen product having the possibility of causing Jam-effect. Once this is the case, initiator and monomer diffusion will be impeded thereby decreasing grafting.

On the other hand results of water retention values (Table 6) reveal that the higher the gelatinization temperature the greater the water retention values. It follows from this that although gelatinization of starch at temperatures higher than $65^{\circ} \mathrm{C}$ adversely affect the magnitude of grafting for reasons cited above, yet these higher temperatures produces gelatinized starch candidates with greater free volume of water absorption; most probably owing to intimate association of homopoly(AN) with these starches. For example, a water retention value of $316 \mathrm{~g}$ water per $1 \mathrm{~g}$ hydrogel is obtained with hydrogel derived from starch gelatinized at $65^{\circ} \mathrm{C}$ followed by polymerization and saponification. This is against a value of $866 \mathrm{~g}$ water per $1 \mathrm{~g}$ hydrogel when the parent material was gelatinized at $85^{\circ} \mathrm{C}$.

Duration of Graft Copolymerization: Table 7 shows the effect of duration of the polymerization reaction on the graft yield\% and the N\% of both composite and the hydrogels derived from poly (AN)-starch composite via saponification. Also shown in the same table are the results of water retention values of the hydrogels and their dependence on the duration of polymerization.

Results in Table 7 imply that the polymerization reaction commences initially very fast then slows down by time to reach a maximum and then decrease. For example the graft yield attains a value of $82.03 \%$ after 15 min duration. This is against maximum graft yield values of $99.36 \%$ after 150 min reaction duration and $87.73 \%$ after $180 \mathrm{~min}$ reaction duration.

$\mathrm{N} \%$ values for composite increases from 12.3 to $14 \% \mathrm{~N}$ as the duration of polymerization increases from 15 to $180 \mathrm{~min}$. The increment in the nitrogen\% of composite with time could attribute to favorable effect of time for homopolymer formation. Examination of the results of water retention values (Table 6) in the light of the above result, would reveal that water retention value increases exceedingly as the duration of polymerization increases till attains highest value of $920 \mathrm{~g}$ water per $1 \mathrm{~g}$ hydrogel after reaction duration of $150 \mathrm{~min}$ or longer.

The nitrogen\% of composite increase by increasing the duration time. The favorable effect of duration could be associated with provision of better opportunity for formation ceric-starch complex and its further dissociation to yield starch macroradicals. The same holds true for diffusion and adsorption of AN monomer into interior structure of starch which will also undergo increased swelling by duration.

Use of the Hydrogel as Absorbent for Synthetic Urine: Table 8 shows the ability of hydrogels having different N\% due to differences in the graft yield\% of poly (AN)-starch composite from which current 
hydrogels were prepared. Date of water retention value places this hydrogel under superabsorbent since $1 \mathrm{~g}$ of the hydrogel absorbs $920 \mathrm{~g}$ distilled water. Current hydrogels absorb also synthetic urine as is evident from the data concerning the latter; $1 \mathrm{~g}$ of the hydrogel absorbs $38 \mathrm{~mL}$ synthetic urine. These promising results make it worth to prepare hydrogels suitable for utilization as diaper and adsorbent material to remove the dyes and heavy metals from industrial effluents and other wastewater.

\section{REFERENCES}

1. Rosiak, J.M. and P. Ulanski, 1999. Synthesis of hydrogels by irradiation of polymers in aqueous solution. Rad. Phys. Chem., 55: 139.

2. Hubbell. J.A., 1998. Synthetic biodegradable polymers for tissue engineering and drug delivery. Solid State Mater. Sci., 3: 246.

3. Griffith, L.G., 2000. Polymeric biomedicals. Acta Mater., 48: 263.

4. Hoffman, A.S., 2002. Hydrogels for biomedical applications. Advanced Drug Delivery Rev., 43: 3.

5. Rosiak, J.M. and F. Yoshii, 1999. Hydrogels and their medical applications. Nucl. Instr. and Meth. In Phys. Res., B151: 56.

6. Hüttermann, A., M. Zommorodi and K. Reise, 1999. Addition of hydrogels to soil for prolonging the survival of Pinus halepensis seeding subjected to drought. Soil and Tillage Res., 50: 295.

7. Wang, Y.T., 1989. Medium and hydrogel affect production and wilting of tropical ornamental plants. Hort. Sci., 24: 941.

8. Huglin, M.B. and M. B. Zakaria, 1986. Swelling properties of copolymeric hydrogels prepared by gamma irradiation. J. Appl. Polym. Sci., 31: 457.
9. Yoshii, F., Y. Zhanshan, K. Isobe, K. Shinozaki and K. Makuuchi, 1999. Electron beam crosslimked PEO and PEO/PVA hydrogels for wound dressing. Rad, Phys. Chem., 55: 133.

10. Cascone, M.G., N. Barbani, C. Cristallini, P. Giusti and L. Lazzeri, 2001. Bioartificial polymeric materials based on polysaccharides. J. Biomater. Sci. Polym., 12: 267.

11. Chen, J., S. Jo and K. Park, 1995. Polysaccharide hydrogels for protein drug delivery. Carbohydrate Polymers, 28: 69.

12. Teli, M.D., R. Paul and P.D. Paradeshi, 2001. Superabsorbent polymers: Properties and Applications. Ind. Text. J., 9: 15.

13. Weaver, M.O., R.R. Montgomery, L.D. Miller, V.E. Sohns, G.F. Fanta and W.M. Doane, 1977. A Practical process for preparation of super slurper, a starch-based polymer a large capacity to absorb water. Starch, 12: 410.

14. Khalil, M.I., Kh. M. Mostafa and A. Hebeish, 1993. Graft polymerization of acrylamide onto maize starch using potassium persulphate as initiator. Die Angewandte Makromolekulare Chemie, 213: 43.

15. Castel, D., A. Ricard and R. Audebert, 1990. Swelling of anionic and cationic starch-based superabsorbents in water and saline solution. J. Appl. Polym. Sci., 39: 11.

16. Vera-Pacheco, M., H. Vazquez- Torres and G. Canche- Escamilia, 1993. Preparation and characterization of hydrogels obtained by grafting of acrylonitrile onto cassava starch by ceric ion initiation. J. Appl. Polym. Sci., 47: 53. 